\title{
Summary of the Space Coordinate Measuring Technology Via Robots
}

\author{
Li Qing $^{1}$, Zhou Yu-Feng ${ }^{2}$, Wu Fang ${ }^{3}$ \\ ${ }^{I}$ (School of Mechanical Engineering, Shanghai University of Engineering Science, China) \\ ${ }^{2}$ (School of Mechanical Engineering, Shanghai University of Engineering Science, China) \\ ${ }^{3}$ (School of Mechanical Engineering, Shanghai University of Engineering Science, China)
}

\begin{abstract}
The space coordinate measuring systems such as coordinate measuring machine, electronic theodolite, laser scanner and online visual measuring are gradually applied to reverse engineering, but as the demand of measuring range, accuracy and measuring environment to increase highly, the existing technology cannot meet the industrial demand. Therefore, the space coordinate measuring system via industrial robot takes advantage of the high flexibility, high efficiency, and equipping with a variety of sensors to satisfy the large scale and automatic measuring in complex environment. In this paper, the systematic review about the space coordinate measuring technology via robots is conducted, and the state of space coordinate measuring technology via robots is elaborated. then the difficulties in the technical theory and application is analyzed.
\end{abstract}

Keyword: Coordinate measuring, Industrial robots, Precision measuring, Reverse engineering

\section{Introduction}

With the development of the national economy and advanced manufacturing technology, and vigorously support the development of major projects and the aerospace, shipbuilding built boats, wind power and deep sea exploration, more and more parts related to the manufacture and measurement technology of complex surface of large size. These parts in the process of manufacturing, the precision of the final forming surface have strict requirements ${ }^{[1]}$, for this kind of parts processing quality must be measured and tested, so as to ensure the performance of the product. The traditional measurement technology can only provide a single measure of specific scope of work, and cannot meet the needs of complex measurement tasks in practical industrial applications, especially for the measurement of space larger size parts more difficult to do. If the different measuring range, different measurement accuracy of the organic integration of a variety of measurement methods, will be able to better meet the needs of the industry. The robot can not only carry a variety of measurement equipment, but also the multivariate data unified to robot coordinate, and with high flexibility and high efficiency, so it can be used as distance measuring terminal measurement system.

\section{Introduction of traditional coordinate measuring technology}

According to statistics, currently the world in the field of high-end equipment design and manufacturing technology, such as the design and manufacture of aircraft turbofan engine blade surface shape, the submarine propeller and the wind turbine blades and other products, more than $70 \%$ are based on the digestion and absorption of other developed countries or other advanced products, and then to realize the imitation and improvement. For the design and development of complex curved surface parts, the most efficient way is to realize the reverse engineering (GRE). A typical GRE process including data acquisition, preprocessing, segmentation and surface fitting, establish CAD model 4 steps $^{[2]}$, including data acquisition is the first step of the measurement process is a key step, directly affects the efficiency, accuracy and stability of the final measurement.

According to the different methods of data acquisition, measurement technology can be divided into two types: contact and non-contact measurement, and various measurement data acquisition methods are shown in Table $1^{[3]}$. Only contact measurement and non-contact measurement methods provide measurement single specific scope of work, and cannot meet the needs of complex measurement tasks in practical industrial applications, especially for the measurement of space larger size parts more difficult to do. If the different measuring range, different measurement accuracy of the organic integration of a variety of measurement methods, will be able to better meet the needs of the industry. 
Table 1. Partial coordinate measuring technology in industrial application

\begin{tabular}{|c|c|c|c|}
\hline $\begin{array}{l}\text { measuring } \\
\text { method }\end{array}$ & principle & Advantage & disadvantage \\
\hline $\begin{array}{c}\text { Three } \\
\text { coordinate } \\
\text { measuring } \\
\text { machine } \\
\end{array}$ & $\begin{array}{l}\text { Three dimensional } \\
\text { coordinates of spatial points in } \\
\text { Cartesian coordinate system }\end{array}$ & $\begin{array}{l}\text { The measurement precision is high, } \\
\text { the technical condition is relatively } \\
\text { mature }\end{array}$ & $\begin{array}{l}\text { The measuring speed is very } \\
\text { slow, the artificial intervention is } \\
\text { many, the versatility is poor, the } \\
\text { operation process is tedious }\end{array}$ \\
\hline $\begin{array}{l}\text { Robot joint } \\
\text { arm }\end{array}$ & $\begin{array}{l}\text { In the non-orthogonal } \\
\text { coordinate system, the } \\
\text { coordinates are obtained by } \\
\text { solving the kinematics of the } \\
\text { robot }\end{array}$ & $\begin{array}{l}\text { The utility model has the } \\
\text { advantages of simple structure, } \\
\text { small size, large measuring range, } \\
\text { convenient use in the field and } \\
\text { strong measurement flexibility }\end{array}$ & $\begin{array}{l}\text { With the increase of arm length, } \\
\text { the rotation error and angular } \\
\text { motion error of the joint are } \\
\text { enlarged, and the measurement } \\
\text { efficiency is relatively low }\end{array}$ \\
\hline $\begin{array}{l}\text { Laser } \\
\text { ranging }\end{array}$ & $\begin{array}{l}\text { The polar coordinates of the } \\
\text { spatial points are obtained }\end{array}$ & $\begin{array}{l}\text { Relatively simple, high precision, } \\
\text { high speed data acquisition }\end{array}$ & $\begin{array}{l}\text { The measurement process needs } \\
\text { to be well planned in advance, } \\
\text { and the base station will have a } \\
\text { great impact on the measurement } \\
\text { accuracy }\end{array}$ \\
\hline $\begin{array}{l}\text { Structured } \\
\text { light } \\
\text { measurement }\end{array}$ & $\begin{array}{l}\text { The position of the spatial } \\
\text { point is solved by } \\
\text { demodulating the grating } \\
\text { pattern projected onto the } \\
\text { measured surface }\end{array}$ & $\begin{array}{l}\text { High acquisition speed, high } \\
\text { precision, performance depends on } \\
\text { ambient light }\end{array}$ & $\begin{array}{l}\text { The measurement accuracy is } \\
\text { affected by the environment, the } \\
\text { calculation is complex, the } \\
\text { occlusion and shadow data is } \\
\text { lost, and the cost is high }\end{array}$ \\
\hline $\begin{array}{l}\text { Stereo vision } \\
\text { measurement }\end{array}$ & $\begin{array}{l}\text { Calculate the position } \\
\text { deviation between the } \\
\text { corresponding points of the } \\
\text { image and get the 3D } \\
\text { geometric information of the } \\
\text { object }\end{array}$ & $\begin{array}{l}\text { Simple and cheap, high precision } \\
\text { measurement target }\end{array}$ & $\begin{array}{l}\text { The calculation is complex, the } \\
\text { data points are sparse, the } \\
\text { requirement of the measurement } \\
\text { environment is high, and the } \\
\text { data acquisition rate is low }\end{array}$ \\
\hline Indoor GPS & $\begin{array}{l}\text { By measuring the infrared } \\
\text { laser signal emitted by more } \\
\text { than two transmitters, the } \\
\text { three-dimensional coordinate } \\
\text { of the received sensor is } \\
\text { solved }\end{array}$ & $\begin{array}{l}\text { The measurement accuracy is high, } \\
\text { and it can be used for simultaneous } \\
\text { measurement of multiple tasks }\end{array}$ & $\begin{array}{l}\text { It is difficult to avoid the errors } \\
\text { in the process of establishing the } \\
\text { system, so it is difficult to avoid } \\
\text { the error of the measurement of } \\
\text { ambient temperature and } \\
\text { pressure }\end{array}$ \\
\hline
\end{tabular}

From the point of view of engineering application, the current and future period of time the development trend is the large size measurement and small close range measurement combination, constitute a combination measurement system, the spatial coordinate measurement device based and global control means, to establish the global coordinate control and restraint, supplemented by front distance measuring equipment, to achieve different types of measured points (such as blind spots, dense point cloud, morphology etc.) the direct measurement ${ }^{[4]}$. Therefore, based on the space combination measurement system of robot, it is necessary to have a high flexibility and adaptability of the large space coordinate measuring system.

\section{Current situation of space coordinate measurement technology based on Robot}

With the continuous development of science and technology, modern manufacturing industry is facing the high quality, high precision, high intelligence and high efficiency technology development direction, put forward higher requirements on precision measurement and precision machining.

\subsection{Industrial robot joint arm measurement technology}

Industrial robot arm type measuring machine is a new type of non-orthogonal coordinate measuring machine, its angle basis to replace the benchmark, several bars and a probe by the rotating joint are connected in series with one end fixed and the other end to move freely on the space, to form a spherical measuring space. Generally, it consists of a base, 6 joints, 2 arms, and a measurement of the first part, the measurement system has a space of six degrees of freedom, you can easily achieve complex workpiece measurement. The coordinate measuring machine is used as the measuring datum and the coordinate system is used to realize the coordinate measurement. Therefore, the primary parameters of the data acquisition system are the rotation angle of each joint. For example, For example, a company's articulated arm measuring machine as shown in Figure 1, the degree of freedom of the measurement space of the 6 degrees of freedom has been greatly improved in the measurement process, there are few dead angles. At present, the articulated arm measuring machine is widely used in machinery manufacturing, automotive, aerospace and other fields, but the articulated arm measuring machine with arm length increase, angle error and angle error of the joint exercise will be enlarged, and the measurement process still needs the help of fixture, the measuring efficiency is relatively low, artificial consumption, not yet wide application. 


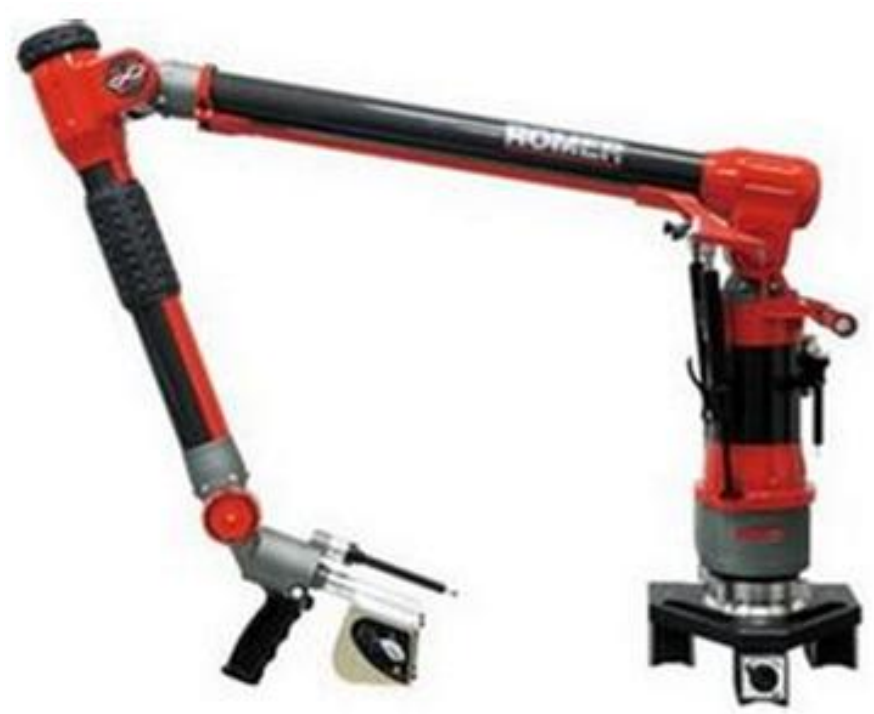

Fig 1. Articulated arm coordinate measuring machine

\section{2 combined measurement technology based on robot}

Industrial robot with four major advantages in the field of measurement, high flexibility, and low price relative to other measurement system; programmable, easy to realize high precision servo control; intelligent terminal, can install a variety of sensors; can improve the measurement efficiency of multi-robot cooperation. Therefore, the spatial coordinate measurement system based on industrial robot has a great advantage in the large size of the combined measurement ${ }^{[5]}$.

The optical measurement system can quickly obtain the coordinates of object surface dense 3D, such as laser scanning, structure light measurement, visual measurement system, so many scholars have done a lot of research on the integrated measurement system and optical measurement robot based on fusion. At present, the robot can be composed of a variety of combinations as shown in Table $2^{[5]}$.

Table 2. Combination of robot based measurement

\begin{tabular}{|c|c|c|}
\hline Combination mode & Measurement object & Author \\
\hline robot + laser scanner & small fan, flange, etc. & $\begin{array}{l}\text { F.J.Brosed }{ }^{[6]} \text {,Jorge } \\
\text { Santolaria }^{[7]-[9]}\end{array}$ \\
\hline robot + structured light sensor & dental model, car model, etc. & $\begin{array}{l}\text { Wu D F } \\
\text { Sansoni }^{[10]-[11]} \text {, Giovanna }\end{array}$ \\
\hline robot + Laser Scanner + camera & mouse, kettle, etc. & $\begin{array}{c}\text { Soren Larsson, Mohanmed R. } \\
\text { Rahayem }^{[14]-[15]}\end{array}$ \\
\hline $\begin{array}{c}\text { robot }+ \text { structure light sensor }+ \\
\text { camera }\end{array}$ & car model, motorcycle fuel tank & Gong $\mathrm{C} \mathrm{H}^{[16]-[17]} \mathrm{Zhu} \mathrm{J} \mathrm{H}^{[18]}$ \\
\hline
\end{tabular}

Research results show that industrial robots can be used as carrier driving element measurement system and measurement equipment, for the practical application of these combined measurement system needs further research, the key technology in three aspects: system calibration, measurement planning and data processing ${ }^{[5]}$.

System calibration refers to components in the measurement system the mechanism, the calibration accuracy directly affects the final accuracy of the measurement system, the calibration of general quasi order: robot calibration, sensor calibration, calibration of robot and sensor location. The measurement system by assembling and calibration, measurement tasks, independent measurement path by first creating a robot, path planning is the key to ensure the measurement work smoothly, the definition of the path should consider all objects covering surface, measurement time, movement cost, path smooth, avoid collision etc.

Data processing refers to the combined measurement based on robot involves multi sensors, multi precision level and multi measuring coordinate data processing problems, due to the use of the workpiece robot combined measurement usually has a large size measurement system based on the collected data due to the complexity of large range and high degree of surface system, the huge amount of data, and the data from in a variety of sensors, so multi-sensor data splicing and effective treatment technology is helpful to improve the measurement accuracy and efficiency. 


\subsection{Multi-robot cooperative measurement technology}

Compared with the single robot system, multi robot cooperation can accomplish more complex tasks, improve the system efficiency and expand the application scope of the system. Especially in the field of measurement of large size parts, single robot is difficult to complete the task of measuring large at the effective time, multi robot measurement system can be a very good solution to this problem, to make multi robot system truly play its advantages, must be supplemented by a reasonable collaborative control strategy. The combined measurement system based on multi robot can realize the function of automatic identification and tracking, and the combination of multiple sensors at the end of the robot is very important for the combined measurement system. At the same time, the global control must meet the real-time pose and accurately measuring each robot, and can real-time control of the robot; measuring method and measuring equipment should provide different range, accuracy, speed, and a plurality of measuring robot work at the same time, in order to improve the measurement efficiency, as shown in figure 2 .

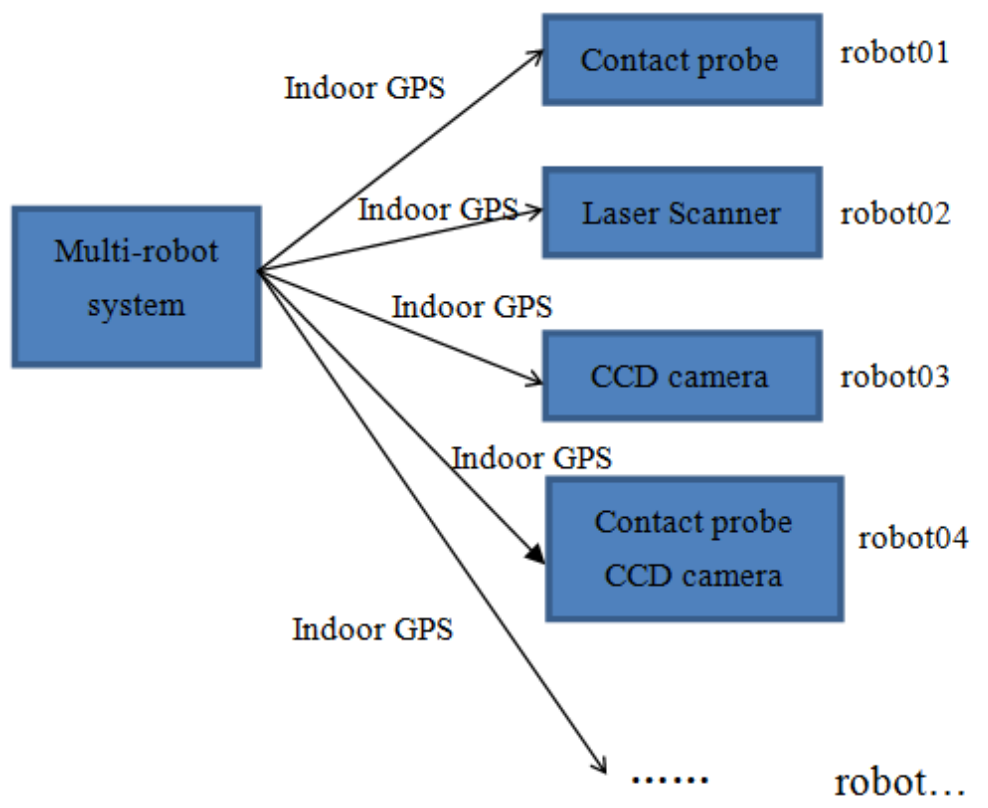

Fig 2. End measuring equipment for multi robot system

Multi robot task allocation (MRTA) is one of the key problems in the research of multi robot system. The research on multi robot task allocation can improve the quality and efficiency of task completion. But in the field of combined measurement, multi robot multi task assignment is still one of the key problems to be solved.

\section{The development trend and difficult problems of the combined measurement technology based on Robot}

Because of the high requirement of the machining quality of the large workpiece in the manufacturing field, a single measurement method cannot meet the needs of the actual industry. It is the trend of current research and development to combine a variety of measuring sensors with different precision and range to form a combined measurement system. The robot with high flexibility, good spatial accessibility and easy control characteristics, is expected to play an important role in the field, but the current ANSI and ISO standards have not set standards of large size coordinate measuring system, so there are two difficult problems in measurement technology.

\subsection{High precision system calibration technology}

Although the combined measurement based on robot with high flexibility, easy to control, can be installed advantages of various sensors, high degree of automation, but the measurement accuracy determines the precision of the whole system, the general accuracy of laser scanner for several microns to tens of microns, and the measurement accuracy of industrial robots for tens to hundreds of microns. To a large extent, the robot error mainly comes from geometric error, compliance error and time-varying thermal error. Therefore, it is one of the key points to improve the accuracy and precision of the calibration of the robot. 


\subsection{Combination measurement system data fusion and splicing}

When measuring large parts, in order to obtain all surface measurement data, usually need to scan the separate area, after each scan will produce data point cloud, and with other data point cloud fusion. The domestic and foreign scholars have conducted in-depth research on multiple data point cloud splicing technology, with group ${ }^{[19]}$ and Jian-wei $\mathrm{Liu}^{[20]} 3 \mathrm{D}$ scattered point cloud registration through artificial landmarks alignment, Tahir Rabbani ${ }^{[21]}$ and Wen-meng Fan ${ }^{[22]}$ to achieve the point cloud data acquisition precision stitching multiple optical sensors. Jie Shao ${ }^{[23]}$ of 3D laser point cloud and CCD image fusion precision is studied, but because of the point cloud data acquisition of multi robot integrated measurement system with large scale, different point cloud density precision characteristics, so a variety of sensors and high dimensional precision data splicing technology is based on one of the research directions combined measurement system of robot.

\section{Conclusion}

Industrial robots have become the supporting technology of advanced manufacturing industry, but also an important symbol of a country's manufacturing level. Review of measurement technology based on robot, analyzes the key technology of the system calibration, measurement planning and data processing, based on the combined spatial coordinate measurement of multi robot system is the future trend of development, reverse engineering can be applied to the unknown prior CAD model. The combined spatial coordinate measurement is a research hotspot in recent years, especially the rapid development of major projects of large aircraft, 10000 ton ships, combined measurement robot is one of the main developing direction of industrial measurement based on the future, and will move toward high precision and high efficiency, intelligent direction of development.

\section{Reference}

[1] Kjellander J A P, Mohamed Rahayem, An integrated platform for 3D measurement with geometric reverse engineering, Computer-Aided Design and Applications, 2009, 6(6):877-887

[2] Li Y D, Gu P H, Free-form surface inspection techniques state of the art review, Computer-Aided Design, 2004, 36( 13) : 1395-1417

[3] Giovanna Sansoni, Marco Trebeschi, Franco Docchio, State-of-the-art and applications of 3D imaging sensors in industry, Cultural Heritage, Medicine, and Criminal Investigation, 2009, 9(1):568-601

[4] Ye S H, Zhu J G., Present situation and development of large space coordinate measurement, Metrology Journal, 2008, 29( 4A):1-6

[5] Li M F, Ma J H, Research status and development trend of space coordinate measurement technology based on Robot, Mechanical science and technology,2014, 33 (12): 1818-1825

[6] Brosed F J, Santolaria J, Aguilar J J, et al, Laser triangulation sensor and six axes anthropomorphic robot manipulator modelling for the measurement of complex geometry products, Robotics and Computer-Integrated Manufacturing, 2012, 28: 660-67

[7] Santolaria J, Pastor J J, Brosed F J, et al, A one-step intrinsic and extrinsic calibration method for laser line scanner operation in coordinate measuring machines, Measurement Science and Technology, 2009, 20: 07-12

[8] Santolaria J, Guillomía D, Cajal C, et al, Modelling and calibration technique of laser triangulation sensors for integration in robot arms and articulated arm coordinate measuring machines, Sensors, 2009, 9: 7374-7396

[9] Santolaria J, Aguilar Juan-Jose, Yague Jose-Antonio, et al, Kinematic parameter estimation technique for calibration and repeatability improvement of articulated arm coordinate measuring machines, Precision Engineering, 2008, 32: 251-268

[10] Wu D F, Li A G, Ma Z, et al, Novel approach to calibrate main body of a three-dimensional scanning robotic system, Journal of Mechanical Engineering, 2011, 47( 17): 9-14

[11] Wu D F, Li A G, Error modeling and compensation approach for three-dimensional surface scanning robot, Journal of Mechanical Engineering, 2012, 48(13):61-67

[12] Sansoni G, Docchio F, Three-dimensional optical measurements and reverse engineering for automotive applications , Robotics and Computer-Integrated Manufacturing, 2004, 20:359-367

[13] Sansoni G, Docchio F, In-field performance of an optical digitizer for the reverse engineering of free-form surfaces, Int J Adv Manuf Technol, 2005, 26:1353-1361

[14] Soren Larsson, Kjellander J A P, Motion control and data capturing for laser scanning with an industrial robot, Robotics and Autonomous Systems, 2006, 54:153-460

[15] Kjellander J A P, Rahayem M, Planar segmentation of data from a laser profile scanner mounted on an industrial robot, Int $J$ Adv Manuf Technol, 2009, 45: 181-190

[16] Gong C H, Yuan J X, Ni J, A self-calibration method for robotic measurement system, Transactions of the ASME, 2000, 122: 174-181

[17] Gong C H, Yuan J X, Ni J, Non geometric error identification and compensation for robotic system by inverse calibration, International Journal of Machine Tools \& Manufacture, 2000, 40: 2119-2137

[18] Zhu J G, Guo L, Liu C J, et al, Measurement system of flexible electronic checking fixture on robot, Optics and Precision Engineering, $2011,19(8): 1787-1793$

[19] Ren T Q, Zhao Y H, Gong C Z, et al, Unconstrained registration of 3-D scattered point clouds for free-form shape measurement, Optics and Precision Engineering, 2013, 21( 5) : 1234-1243

[20] Liu J W, Liang J, Liang X H, et al, Industrial vision measuring system for large dimension work-pieces, Optics and Precision Engineering, 2010, 18( 1):126-134

[21] Rabbani T, Dijkman S, Frank V D H, et al, An integrated approach for modelling and global registration of point clouds, ISPRS Journal of Photogrammetry \& Remote Sensing, 2007, 61:355-370

[22] Meng F W, Wu L S. Registration of unorganized point clouds by inheriting and optimizing algorithm, Optics and Precision Engineering, 2009, 17 ( 4 ) : 825-831

[23] Shao J, Zhang A W, Wang S M, et al. Research on fusion of 3D laser point clouds and CCD image, Chinese Journal of Lasers, 2013, $40(5): 1-8$ 